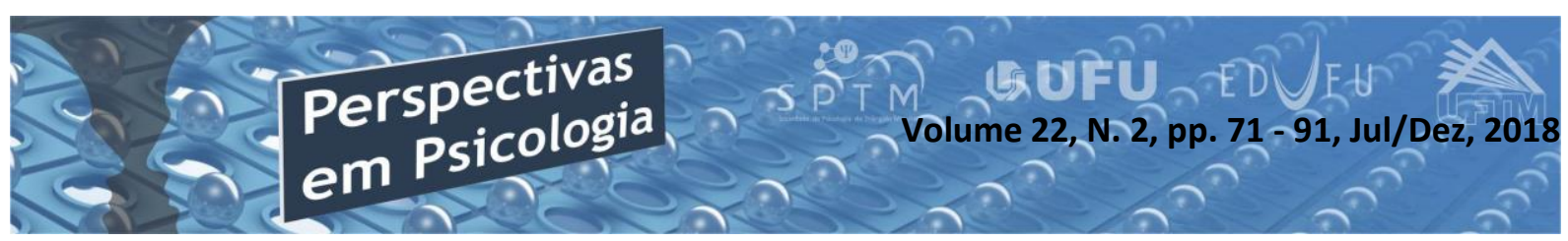

\title{
DO ENCLAUSURAMENTO À AUTONOMIA: O ACOMPANHAMENTO TERAPÊUTICO NA REFORMA PSIQUIÁTRICA
}

\author{
Juliana Aguiar dos Santos Baptista \\ Rebeca Juliane da Silva Cavalcante \\ Maicon Barbosa \\ (Centro Universitário Augusto Motta - UNISUAM - Rio de Janeiro - RJ)
}

\begin{abstract}
Resumo
Esse artigo objetiva compreender a relação entre o Acompanhamento Terapêutico e a Reforma Psiquiátrica brasileira, a partir de uma revisão bibliográfica de artigos publicados em revistas acadêmicas da área de Psicologia. Foram analisados 26 artigos, publicados entre 2005 e 2016, encontrados no Scielo, Pepsic e Google acadêmico. A partir do material levantado, foram construídos quatro eixos de análise: autonomia e garantia de direitos; a Reforma Psiquiátrica $e$ o Acompanhamento Terapêutico; o acompanhante terapêutico e sua relação com o acompanhado; e o espaço urbano na clínica do AT. Conclui-se que o AT teve papel importante no processo de desinstitucionalização da loucura, contrapondo-se ao cotidiano enclausurado das instituições manicomiais e construindo outras relações entre a Saúde Mental e a cidade.
\end{abstract}

Palavras-chave: Acompanhamento terapêutico; psicologia; Reforma psiquiátrica; espaço urbano; Saúde mental.

\section{Abstract}

\section{From enclosure to autonomy: Therapeutic Accompaniment in Psychiatric Reform}

This article aims at the relationship between Therapeutic Accompaniment and Brazilian Psychiatric Reform, based on a bibliographic review of articles published in academic journals in the area of Psychology. We analyzed 26 articles, published between 2005 and 2016, found in Scielo, Pepsic and Google Scholar. From the material raised, four axes of analysis were constructed: autonomy and guarantee of rights; Psychiatric Reform and Therapeutic Accompaniment; the therapeutic companion and his relation with the companion; and urban space in the AT clinic. It was concluded that TA had an important role in the process of deinstitutionalisation of insanity, in opposition to the cloistered daily life of mental institutions and building other relationships between Mental Health and the city.

Keywords: Therapeutic accompaniment; psychology; Psychiatric reform; urban space; mental health.

\section{Introdução}

O presente artigo foi elaborado a partir de uma pesquisa de conclusão de curso de graduação em psicologia, realizada no Centro Universitário Augusto Motta, na cidade do Rio de Janeiro. O estudo que deu origem a esse artigo teve como foco 
compreender como, nos últimos anos, revistas acadêmicas de psicologia vêm abordando a perspectiva do Acompanhamento Terapêutico (AT) no contexto da Reforma Psiquiátrica no Brasil. O levantamento e a análise de pesquisas recentes podem cooperar para entendermos o grau de visibilidade que o AT possui atualmente no campo acadêmico da Psicologia, em sua articulação com o campo da Saúde Mental.

A Reforma Psiquiátrica é um marco político, teórico e prático no campo da Saúde Mental (Hirdes, 2009). Com a Declaração de Caracas, de 1990, os países da América latina se comprometeram com uma reforma que reestruturaria o modelo psiquiátrico até então utilizado, abrindo espaço para os usuários exercerem seus direitos e sua cidadania (Hirdes, 2009). No Brasil, as Conferências Nacionais de Saúde e Saúde Mental são consideradas marcos democráticos fundamentais para a construção e efetivação da Reforma Psiquiátrica.

A partir de uma revisão bibliográfica, Hirdes (2009) analisa o termo desinstitucionalização em três distintas interpretações: desospitalização, desassistência e desconstrução. No que se refere a desospitalização há uma crítica ao modelo hegemônico hospitalocêntrico. A autora aponta que a desinstitucionalização também foi entendida por alguns como desassistência, que seria não prestar nenhum tipo de assistência aos pacientes, deixando-os sem nenhum tipo de atenção e cuidado. A desconstrução refere-se à crítica intensa ao saber médico/psiquiátrico: nesse sentido, a autora refere-se à prática de desconstrução de Franco Basaglia no hospital de Gorizia, na Itália, que afirmou uma forma democrática de trabalhar com a psiquiatria. Após a Reforma Sanitária, que mais tarde culminou no SUS e a Reforma Psiquiátrica no Brasil, serviços de substituição ao modelo manicomial foram criados. Entre eles o CAPS, serviços de residências terapêuticos, ambulatórios, programas sociais de ligação à cultura e inclusão social. Hirdes (2009) chama a atenção para o conceito de reforma substitutiva, que tem pretensão de prestar assistência e cuidado ao usuário de saúde mental em todo seu processo de vida, incluindo a família.

$$
\text { Simões e Kirschbaum (2005) }
$$

fizeram uma análise do que já encontramos como pesquisa referente ao acompanhamento terapêutico no Brasil entre 1960 e 2003, e para isso, fizeram um levantamento dos aspectos históricos. Os estudos revisados pelos autores abordam a importância de o usuário de saúde mental ser visto como sujeito, que têm autonomia e direito de exercê-la, inclusive participando 


\section{PSIQUIÁTRICA}

das decisões médicas sobre seu corpo e o tratamento. Na década de 1960 a loucura passou a ser vista como investimento lucrativo, o que colaborou com um aumento expressivo no número de pacientes em hospitais psiquiátricos privados, dificultando o surgimento de outras medidas, não hospitalocêntricas, em oposição ao modelo manicomial (Simões \& Kirschbaum, 2005). Na década de 1970 o modelo hospitalocêntrico passou a ser criticado de maneira mais incisiva. Mesmo assim, com todas as críticas sofridas, esse modelo continuou sendo hegemônico. Em meados dos anos 1970, foram apontadas questões sobre a falta de eficiência do modelo até então instituído. A partir da década de 1980 as críticas ao modelo instituído ganham mais espaço, dando forma ao que se chamaria de Reforma Psiquiátrica. Ao final da década de 1980 e começo da década de 1990 surgiram regulamentações, que tinham como propósito políticas de saúde mental mais eficazes do que aquelas, até então, disponíveis. Durante a década de 1990 houve três grandes destaques que colaboraram com o progresso da Reforma Psiquiátrica: a forma de trabalhar com a loucura deveria evidenciar propósitos e resultados efetivos para os sujeitos atendidos; a insistência nos propósitos relacionados à reforma e uma nova forma de pensar o louco por parte da ciência. Esse processo e essas experiências colaboraram de forma importante para o surgimento do Acompanhamento Terapêutico, que se trata de uma maneira diferente de intervir, comparada ao modelo hospitalocêntrico e manicomial.

Simões e Kirschbaum (2005) apresentam uma análise histórica da função do acompanhante terapêutico, que pode ser entendida em três momentos, nomeados de diferentes formas: atendente psiquiátrico, auxiliar psiquiátrico e amigo qualificado. As três funções se diferenciam discretamente uma da outra: o atendente psiquiátrico acompanhava o paciente dentro e fora da instituição e em atividades estabelecidas por aquele campo institucional; o auxiliar psiquiátrico prestava atendimento durante todo o dia-adia do paciente; e o amigo qualificado acompanhava o paciente em atividades que não eram propostas pela instituição (Simões \& Kirschbaum, 2005).

Considerando o AT um dispositivo de atenção psicossocial em Saúde Mental, Pitiá e Furegato (2009) discutem a necessidade de uma gama de serviços em rede, que permitam o desenvolvimento da perspectiva de vida do sujeito, considerando todo contexto no qual ele está inserido. As autoras notam que é bastante frequente a separação entre saúde mental e saúde física, dicotomia que favorece uma hierarquização da dimensão biológica da 
saúde. As questões referentes à saúde mental acabam ficando mais distantes da atenção nos serviços prestados, quando se privilegia o atendimento de demandas de saúde física. No entanto, faz-se necessário que os serviços de saúde mental estejam em consonância com os outros serviços, fazendo parte de uma rede única de atenção, que permita ao sujeito uma imersão completa em um sistema eficaz (Pitiá \& Furegato, 2009).

A atenção aos usuários que vivenciam transtornos mentais graves precisa funcionar em caráter interdisciplinar e promover cidadania, facilitando a reabilitação e reinserção social. Dessa forma, como cidadã, a pessoa com sofrimento psíquico coloca em prática sua autonomia, realizando atividades do dia a dia.

O AT é uma forma de fazer uma clínica extra-hospitalar atenta às singularidades de cada sujeito, que aposta na inserção comunitária, possibilitando outras formas de socialização na imprevisibilidade da cidade, que difere radicalmente do espaço enclausurado da instituição manicomial. O AT é entendido por Pitiá e Furegato (2009) como uma estratégia interdisciplinar que tem como objetivo criar vínculos entre o usuário e a comunidade, em uma experiência antissegregacionista.
Wachs, Jardim, Paulon e Resende (2010) assinalam a desinstitucionalização da loucura como o propósito da Reforma Psiquiátrica, intensificada no ato de percorrer a cidade e ser atravessado por outras pessoas e novos espaços.

Esse modo de circular também mobiliza as pessoas que transitam por esses lugares, ou seja, também existe um olhar do outro que acaba atravessado esses espaços: essas pessoas que antes eram enclausuradas passam a ter a oportunidade no AT de vivenciar espaços onde os outros que o ocupam não o partilhavam com a loucura. Essa circulação da loucura pela cidade proporcionada pelo AT abre-se ao encontro dos acompanhados com novos territórios, experiência fundamental para a produção de uma autonomia impossibilitada pelo enclausuramento da instituição manicomial.

A partir dessas considerações iniciais, o presente artigo tem como objetivo compreender a relação entre o Acompanhamento Terapêutico e a Reforma Psiquiátrica brasileira, a partir de uma revisão bibliográfica de artigos publicados em revistas acadêmicas da área de Psicologia.

Analisar a articulação entre o Acompanhamento Terapêutico e a Reforma Psiquiátrica é primordial para a formação em Psicologia, considerando que a Saúde 
Mental se configura como importante campo de lutas e de práticas para psicólogas e psicólogos no Brasil, tanto em relação à garantia de direitos às pessoas com transtornos mentais graves, quanto na efetivação de uma atenção psicossocial no contexto do SUS.

\section{Método}

Os artigos utilizados no presente estudo foram pesquisados nas bases de dados Scielo, Pepsic e Google acadêmico, por meio dos seguintes descritores: Reforma psiquiátrica, Acompanhamento terapêutico e Psicologia. Foram filtrados estudos ocorridos entre 2005 e 2016. A revisão bibliográfica de perspectiva qualitativa foi realizada a partir da literatura recuperada nas plataformas mencionadas. As fontes utilizadas foram produções científicas da área de Psicologia que apresentam uma articulação entre o Acompanhamento e a Reforma Psiquiátrica. Vinte e seis artigos foram analisados para construir a presente revisão. Após o levantamento e leitura do material, foi realizada uma categorização dos temas a serem analisados, e em seguida os artigos foram agrupados por eixos temáticos, com o objetivo de organizar a discussão em quatro momentos: (1) autonomia e garantia de direitos, (2) a Reforma Psiquiátrica e o Acompanhamento Terapêutico, (3) o acompanhante terapêutico e sua relação com o acompanhado e; (4) o espaço urbano na clínica do AT. Em cada eixo temático apresentamos pontos importante dos artigos, com base na análise minuciosa do material selecionado.

\section{Autonomia e garantia de}

\section{direitos}

Nessa seção, foram analisados estudos que discutem a valorização da singularidade do sujeito, a reinserção social, a reabilitação e o exercício da autonomia, bem como os direitos dos acompanhados como cidadãos. Com base na obra de Michel Foucault, Chauí-Berlink (2010) afirma que o louco passou a ser considerado o oposto do detentor de razão na modernidade ocidental: a loucura era tratada pela psiquiatria como motivo para alienação e exclusão social. Para se contrapor a essa ideia, a autora critica a concepção de alienação e afirma uma devida atenção à singularidade subjetiva e à autonomia como direito das pessoas com sofrimento psíquico. A autora argumenta que para haver luta contra a exclusão, fazse necessária uma reconstrução da subjetividade: nesse sentido, analisa criticamente a concepção de doença mental como detrito social a ser excluído e isolado em instituições. 
Também a partir das concepções de Michel Foucault (2012), em A história da loucura, Pacheco e Menezes (2014) afirmam que o louco, com o surgimento e disseminação do capitalismo, passa a ser considerado como improdutivo, além de ser visto como uma ameaça aos campos social e econômico. Na passagem do Século XIX e início do Século XX, os loucos passaram a ser tomados, de maneira definitiva, como doentes mentais e nesse momento se instaurou a medicalização, articulada às inúmeras práticas de assujeitamento que constituíam as instituições manicomiais (Pacheco \& Menezes, 2014). Aos poucos, com as mudanças que a Reforma Psiquiátrica preconiza, a possibilidade de uma rede de atenção começa a ser debatida. Os autores citam a desinstitucionalização pautada na Reforma Sanitária como base de contínua mudança e construção de serviços substitutivos.

Gruska e Dimenstein (2015) atentam para a reinserção do usuário em um meio social repleto de normas e exclusão, que pode limitá-lo no tange ao processo de convivência com a diferença. Em alguns casos, pode haver despreparo da comunidade para lidar com a alteridade. Aqui ressaltamos a importância do espaço, que não depende somente do usuário acompanhado, mas também das pessoas com as quais ele se encontrará. Nesse momento pode haver propagação de violência voltada para o usuário, que pode se sentir prejudicado, incapaz e acaba por evitar quaisquer tipos de interação. Faz-se necessário exercitar ações de cidadania na comunidade para que o processo se torne menos difícil de ser desenvolvido plenamente. Nesse caso, torna-se primordial um entendimento biopsicossocial e não somente técnico, encontrando formas de trabalhar visando integralidade, e não somente o usuário individualmente. $\mathrm{O}$ desafio posto pelo AT seria recusar os processos de exclusão do sujeito acompanhado e investir na alteridade, no encontro com a diferença na cidade. A intervenção proposta pelo AT tem como foco aumentar a possibilidade de vínculos, promovendo saúde fora do campo institucional (Gruska \& Dimenstein, 2015).

Em uma análise feita através da perspectiva da esquizoanálise, Muylaert (2006) ressalta a importância de produzir cidadania e novas formas de existir. Entendendo o AT como dispositivo clínico, a autora nos diz que essa prática pode potencializar e produzir vida. Não se trata de reduzir o AT a uma teoria desconectada das experiências concretas dos acompanhados, pois esse movimento seria uma forma despotencializada de praticar a clínica, mesmo fora dos muros da instituição. A potência desse dispositivo 
aumenta as condições efetivas de acolhimento das diversidades e singularidades, permitindo que a clínica do AT seja pautada em processos de criação de outras formas de estar no mundo, de maneira autogestiva (Muylaert, 2006).

\section{A Reforma Psiquiátrica e o Acompanhamento Terapêutico}

Para desenvolver a análise da presente seção foram usados artigos que discutem o histórico do Acompanhamento Terapêutico, bem como o processo de Reforma Psiquiátrica e desenvolvimento de estratégias de atenção psicossocial. O Acompanhamento Terapêutico, para Oliveira (2013), segue o caminho proposto pela Reforma Psiquiátrica porque tem como objetivo permitir ao sujeito exercer sua autonomia, seu direito de ir e vir, de se relacionar com as pessoas e com o espaço que ocupa, de consumir e de apropriar-se de si. A esse processo, o autor dá o nome de desinstitucionalização da loucura, onde o sujeito institucionalizado precisa ser visto como cidadão. Em sua análise, Oliveira (2013) conta o caso de Edson, morador de uma residência terapêutica, que ao perceber que tinha posse de uma renda, criou planos e metas durante a experiência de acompanhamento. Edson se deu o direito de ter um espaço que fosse seu e planejou morar sozinho, pagando aluguel. Além de exercer sua autonomia de consumidor, Edson durante a execução de suas metas, conheceu pessoas, interagiu com elas e estabeleceu relacionamentos, criando seu território.

Neto e Amarante (2013) falam do processo de mudança nos serviços que ocorreu durante os anos para que houvesse alinhamento com as diretrizes pertinentes à Reforma Psiquiátrica e apontam o Acompanhamento Terapêutico como um dos mecanismos não-asilares, que visam promover a reinserção e a construção de vínculos entre o usuário e o os espaços comunitários. Os autores criticam a falta de amplitude no que se refere à atenção psicossocial: afirmam que o ideal seria promover redes de atendimento que assistam o usuário em todos os campos de sua vida, com o intuito de promover bemestar, ao invés de reduzir o cuidado à ideia de um centro de tratamento. Para os autores, o Núcleo de Apoio à Saúde da Família (NASF) tem potencial para abranger essa assistência integral: nesse sentido, ressaltam a importância de uma atenção singular, realizada também no âmbito da Atenção Básica em Saúde.

Paravidini e Alvarenga (2008) ressaltam que o processo histórico de Reforma e as experiências além do espaço asilar se tornaram referências no cuidado em saúde mental. Os autores apontam um processo em que, no início, o cargo de 
auxiliar psiquiátrico não contava com nenhuma formação, mas depois, com um maior número de cursos de Psicologia disponibilizados, esse cenário mudou, possibilitando a construção de equipes com experiências na área de saúde mental. Como afirmam os autores, faz-se necessário discutir a proposta de fundamentar o AT em outras vertentes teórico-práticas que não se embasem somente na Psicanálise, considerando que boa parte da literatura encontrada trata o AT em perspectivas psicanalíticas.

A partir de uma revisão bibliográfica sobre a história do AT e de uma pesquisa entre trabalhadores da saúde mental em Belo Horizonte, Nogueira (2009) entende o AT como uma forma de fazer clínica que transcende a prática medicamentosa e trancafiada, tendo como propósito substituir o modelo hegemônico de tratamento em saúde mental instaurado historicamente. Na pesquisa da constituição histórica do AT em Belo Horizonte, ao abordar práticas de estágio de estudantes de graduação em Psicologia, a autora observa que em grande parte das experiências, os atendimentos eram individuais, envolviam os familiares e orientavam-se pelo enfoque psicanalítico (Nogueira, 2009).

Em uma perspectiva de formação do AT e o seu funcionamento institucional no Centro de Convivência e Cooperativa
(CECCO) do município de São Paulo, Herman (2010) concebe o AT como uma possibilidade efetiva de oferta de laço social, e em concordância com Hirdes (2009), aponta Franco Basaglia como percussor de uma forma de tratamento contrária à lógica manicomial. A partir de Basaglia o poder exercido pelo saber médico passou a ser analisado e criticado: o trabalho feito por Basaglia em Trieste foi considerado fundamental, passando por diferentes etapas: primeiramente, a equipe trabalha no interior da instituição e depois, começou, aos poucos, a estabelecer relações entre o interior e o exterior da instituição. Os usuários passaram a ser nomeados como hóspedes, por inspirar mais respeito do que os estereótipos já criados até então. A atitude de Basaglia permitiu que antigos paradigmas excludentes fossem seriamente criticados e recusados. Como a horizontalização da relação entre médicos e pacientes, aos poucos, tornou-se real a ideia de que os pacientes tinham direito de exercer suas autonomias, participando de decisões em seus próprios tratamentos (Herman, 2010).

Em uma análise que discute a intervenção do AT, Estellita-Lins, Oliveira e Coutinho (2006) ressaltam a importância de encarar o suicídio e a depressão como algo não somente médico, mas também de responsabilidade da comunidade na qual o 


\section{PSIQUIÁTRICA}

sujeito está inserido. Tendo em vista as ramificações dos impactos do suicídio, não se pode desconsiderar elementos culturais e sociais que o constitui. Para os autores, algumas pessoas que cometem suicídio podem sofrer de algum transtorno psíquico. Aqui, mais uma vez, faz-se necessário o aproveitamento de uma rede, onde profissionais possam se comunicar entre si e intervir em consonância. Para esses autores, nos casos em que o usuário tenha tentado suicídio anteriormente ou apresentando ideação suicida, cabe ao acompanhante terapêutico investigar junto ao sujeito a forma como este pretende executar a ação para tirar sua vida. O primordial é o estabelecimento de confiança entre o acompanhante, o acompanhado, seus familiares e outras pessoas importantes para o sujeito (Estellita-Lins, Oliveira \& Coutinho, 2006).

Em uma análise feita por Silva e Silva (2006) o AT é concebido como uma atividade que não fica restrita ao espaço institucional e estabelece uma relação entre saúde e subjetividade, sendo considerado uma estratégia de intervenção e de cuidado em Saúde Mental. A partir da obra de Edgar Morin, os autores diferenciam a noção de programa, e a concepção de estratégia: os programas são mais restritos e instituídos, reproduzindo uma lógica adaptativa; e as estratégias apresentam possibilidades mais abrangentes podendo usar os espaços urbanos como meio para outras produções de sentido. Ao longo do processo histórico, há uma mudança nas formas de poder que passam de regimes disciplinares para regimes de controle; o usuário passa a se libertar dos muros do manicômio, mas leva os psicofármacos com ele. De modo crítico, os autores nos dizem que o Acompanhante Terapêutico era responsável, em muitos momentos, apenas pela administração dos medicamentos ao usuário: além de controle físico era também exercido controle químico. Com a ideia de um "ambiente humanizado" para usuários, a quebra da hierarquia foi um caminho que passou pelos hospitais-dia, pelas comunidades terapêuticas, até chegar ao AT. As equipes técnicas passariam a repensar seu modelo de atuação, com a ideia de romper o modelo hierárquico (Silva \& Silva, 2006).

O Acompanhamento terapêutico é um fazer clínico, e nesse sentido Gonçalves e Barros (2013) afirmam que o AT poderia ser chamado de "clínica sem muros", onde existe a tentativa de reconstrução de um elo entre a loucura e as cidades, mobilizando forças na própria experiência urbana. Para os autores, a Reforma tem como pretensão não somente a desospitalização, mas também a desinstitucionalização: torna-se necessário reconhecer que a Reforma interferiu nos saberes médicos e psiquiátricos que tinham pretensão de permanecer como detentores de poder. 
Houve uma descentralização do poder médico: a ideia era, de fato, descentralizar o poder e investir em serviços que substituíssem a lógica manicomial, criando redes, ambulatórios e o máximo de atenção psicossocial possível. Assim, a maneira de executar a clínica também se modificou ao ser desinstitucionalizada.

Em uma análise feita por Vasconcelos, Machado e Mendonça Filho (2013), a cidade de Aracaju, em Sergipe, é apontada como referência nacional em Saúde Mental, pois a rede local é pautada nos princípios do SUS e da Reforma Psiquiátrica. Para os autores, o CAPS é um exemplo efetivo de descentralização do modelo médico. Discutindo a relação entre a lógica manicomial e o capitalismo contemporâneo, os autores analisam a produção de "corpos docilizados", que precisam se tornar flexíveis e, acima de tudo, precisam produzir satisfatoriamente. E nesse contexto, um dispositivo como o CAPS afirma-se como produtor de resistência, que permite que outras lógicas, que não a manicomial, sejam exercidas. Os autores entendem que a "derrubada" dos muros físicos hospitalocêntricos não são suficientes, pois existem outros muros manicomiais invisíveis que precisam ser problematizados e derrubados para que seja possível reinventar formas de atuar, inclusive no AT.
Pellicciolli (2014) coloca em questão o discurso que se pretende neutro e científico, mas que produz subjetividades, principalmente quando são proferidos por “especialistas". O autor analisa a lógica de individualização das "doenças mentais", que supostamente seriam originadas exclusivamente no sujeito, e nesse sentido também problematiza o AT, que em alguns momentos já foi utilizado para controle dos acompanhados. Para o autor, o familiarismo surgiu como mais uma das formas de controle, que tinha a pretensão adequar corpos à família e às normas sociais, sob disciplina. $\mathrm{O}$ autor aponta que muitas práticas psicológicas também faziam parte de um conjunto de conhecimentos que tinha como objetivo exercer poder e regular pessoas.

Na perspectiva de Sereno (2012), há muitos argumentos a favor do Acompanhamento Terapêutico, pois, com a Reforma Psiquiátrica, houve redução de leitos em hospitais psiquiátricos e um aumento significativo de CAPS. Entretanto, a falta de investimentos em serviços substitutivos pode levar a equipe a regredir no que tange a cultura manicomial. O Acompanhamento Terapêutico objetiva criar mecanismos que permitam que a pessoa com sofrimento mental usufrua do espaço e de sua própria autonomia. Tendo em vista essas questões, é importante pensar 
numa ética a ser exercida no AT como clínica expandida, que permite um processo de interação que faz parte da redução do mal-estar instaurado, valorizando a singularidade do sujeito. Para a autora, a partir da utilização de uma perspectiva psicanalítica, o AT aposta na transferência e em uma clínica do real cotidiano.

\section{O acompanhante terapêutico e sua relação com o acompanhado}

Com o objetivo de elaborar a presente seção foram examinados artigos que abordam a maneira em que se dá a relação do acompanhante terapêutico e do acompanhado, a fim de analisar os procedimentos e efeitos da relação produzida na subjetividade dos envolvidos na experiência do AT. Silveira (2016) aponta em seu artigo que o objetivo de sua investigação no campo clinico se dá a respeito da relação entre acompanhante e acompanhado por meio do conceito de amizade. O autor chama de dispositivo amizade-clínica a análise das relações de poder que existem no Acompanhamento Terapêutico, que se dão fora dos espaços institucionalizados. Para que esse dispositivo seja bem-sucedido é preciso que a relação se dê na diferença, sustentando possíveis conflitos e a presença da heterogeneidade, permitindo a diversidade dos encontros. A proposta não é pensar em um modelo de amizade simétrica porque não seria diferente de criar relações de poder e os padrões exercidos do modelo familialista, ou seja, relações hierarquizadas dentro do grupo social da família. Dessa forma o autor destaca a importância de outras formas de relação no AT, que constitui processos de subjetivação não necessariamente familiares. $\mathrm{O}$ artigo ressalta como é o funcionamento dessa relação no AT, onde existe uma convivência a partir do cotidiano do acompanhado, levando a relação entre acompanhante e acompanhado a vivenciar o que é distinto entre ambos, criando condições para uma aproximação na diferença. $\mathrm{O}$ autor cita alguns casos de acompanhamentos e conclui que o trabalho do AT aciona uma clínica que opera transformando, na relação acompanhante e acompanhado, formas de percepção e modos de subjetivação. Dessa forma, Silveira (2016) apresenta o acompanhamento terapêutico e a importância da distância na experiência da amizade construída, evidenciando novos modos de se relacionar que esse espaço permite a acompanhante e acompanhado. Relação essa que destaca um cenário de confronto, disparando o que é distinto no outro, retirando-o de sua interação limitada a si mesmo. Assim, essa distância pode beneficiar a relação, promovendo 
singularidade e autonomia para elaborar outros modos de subjetivação.

Chauí-Berlink (2010) aborda o AT e a sua importância na formação do profissional de psicologia, questionando a necessidade de se identificar como profissional influente na construção de subjetividade do outro. Questiona ainda o objetivo do AT sobre o acompanhado e sua relação com a sociedade. $\mathrm{O}$ artigo tem como embasamento as práticas da autora como docente de psicologia e como acompanhante terapêutica. Chauí-Berlink (2010) reconhece a contribuição do AT ao profissional de psicologia, a partir da noção de que o acompanhado possui uma convivência, muitas vezes, excluída da sociedade e esse vínculo criado entre as partes desenvolve um laço social que permite estabelecimento de um campo de troca social. Assim, se dá um processo onde o acompanhado passa a ter sua voz escutada. Chauí-Berlink (2010) conclui então que o AT possibilita ao acompanhado uma reintegração social a partir do trabalho do acompanhante, permitindo práticas de liberdade na sociedade em paralelo ao que é estabelecido em uma relação institucional, proporcionando novas formas de vivenciar relações consigo e com o coletivo.

Palombini (2006) descreve o acompanhamento terapêutico como um dispositivo clinico-político, destacando a importância da imersão na relação do usuário com o acompanhante terapêutico a partir do que é vivido no cotidiano. Foi analisado ainda o aprendizado que é desenvolvido na relação nesse dispositivo e o quanto isso beneficia o trabalho do acompanhante que precisa abandonar velhas práticas e mergulhar na imprevisibilidade que esse dispositivo proporciona. Isso se dá devido ao trajeto vivenciado na cidade, onde ocorre o encontro com outros espaços e possibilidades para o AT. Assim, o usuário e o acompanhante experimentam o processo social gerado pelos diferentes espaços na trajetória dos serviços de Saúde Mental na cidade.

Muylaert (2006) destaca a inovação nas formas de se relacionar criadas a partir dos encontros que percorrem a cidade no AT e é dessa maneira que o acompanhado estabelece um laço com o coletivo. A autora ressalta que as diferenças exercidas nas idas e vindas do coletivo proporcionam uma experimentação do mundo a quem percorre esse espaço, ou seja, na produção do que ocorre na exploração do exercício do AT são elaborados laços e campos onde a transformação do acompanhado se faz possível (Muylaert, 2006).

Varella, Lacerda e Madeira (2006) consideram a importância do AT na possibilidade do acompanhado traçar suas 


\section{PSIQUIÁTRICA}

próprias significações sociais e isso é construído por meio da relação com o acompanhante e o trajeto, ao percorrerem outros territórios: é a circulação entre lugares que permite uma transformação de si. Dessa forma, o acompanhante atua no papel de mediador dos novos lugares a serem explorados, e o espaço de troca que ocorre no papel social do acompanhado é possível devido ao desenvolvimento do trabalho nessa clínica no espaço da cidade.

Pitiá (2013), a partir de uma reflexão a respeito da prática do $\mathrm{AT}$, destaca os objetivos do acompanhamento que abrangem: a reinserção social do indivíduo acompanhado; a percepção da prática como multiversa; e as redes produzidas pelos encontros que ocorrem entre acompanhante e acompanhado. A autora ressalta também os elementos relevantes do ato de acompanhar, que possuem a finalidade de auxiliar no "resgate" da experiência de cidadania do sujeito, como: propor atividades conjuntas, estar com o acompanhado, utilizar a escuta e enxergá-lo integralmente. Dessa forma, a função do AT é trabalhar uma clínica possível ao sujeito que possui dificuldades psicossociais, e essa clínica é possibilitada pela relação acompanhante com acompanhado. O AT possibilita que a dimensão social na constituição subjetiva esteja em evidência a partir de sua prática que intensifica a experiências de sociabilidade. No desenvolvimento dessa rede o acompanhante propicia ao acompanhado a reestruturação do seu planejamento de vida: é através dessa reestruturação, da reabilitação psicossocial do usuário e das relações sociais nos espaços percorridos do cotidiano que se dá o trabalho do AT. A autora discute a importância da ação interdisciplinar no AT a partir da noção de circulação no espaço que a clínica do AT promove, ao propor que o profissional saía de sua zona de conforto e reinvente seu trabalho para atuar nessa clínica sem muros.

Na perspectiva de Ribeiro (2009), o acompanhante tem a missão de se dispor ao outro de forma que o encontro permita ao acompanhado partilhar suas vivências. O acompanhante através do AT e da experiência que se produz pelo transitar no mundo, possibilita a produção de autonomia para o acompanhado, faz-se significante nesse encontro na cidade, gerando um trajeto singular para ambos.

\section{O espaço urbano na clínica do AT}

Com o intuito de examinar a seguinte seção foram analisados artigos que debatem a relação entre o espaço urbano e a produção de subjetividade para aqueles que experimentam o trabalho clínico desdobrado no AT. Palombini (2006) afirma o acompanhamento terapêutico como uma parte do planejamento que 
compõe o processo de desinstitucionalizar a loucura, entendendo que essa experiência clínica combina práticas da psicologia com espaços e tempos da cidade. A autora debate então a pretensão da prática do AT ao inovar as maneiras de atenção à saúde mental, trazendo o questionamento a respeito do sentido em que essas práticas produzem, posicionando-se no sentido contrário a uma sociedade disciplinar, psiquiatrizada, de um mundo que é mais constituído de neurociências que são priorizadas em relação a outras práticas psi, com intenção de disciplinar corpos por meio de medicamentos. Dessa forma, a autora indaga: não seria no sentido contrário disso que o acompanhante se lança pelas ruas com o acompanhado? $\mathrm{O}$ que o acompanhante busca não é romper esses códigos instituídos e modificar as formas de relação? Então a autora afirma que o acompanhamento terapêutico é uma prática citadina, e o espaço urbano se estabelece como lugar de encontro de territórios onde diferentes processos fazem parte da mistura e pluralidade da cidade. Nesse sentido, a cidade pode ser considerada disposta a inúmeras imprevisibilidades que podem provocar estranheza e desconforto. Para a clínica do AT, o imprevisto do espaço urbano produz deslocamentos no território múltiplo da cidade. Assim, o acompanhamento terapêutico é realizado em um espaço aberto aos territórios que se encontram na cidade, constituindo outras práticas urbanas e habilitando a chance de se realizar uma clínica que sustenta conflitos e imprevisibilidades.

$$
\text { Palombini (2009) descreve a }
$$
experiência do AT que se dá entre lugares, em idas e vindas. Muitas vezes esse acompanhamento é convocado precisamente em contextos onde $\mathrm{o}$ deslocamento pelo espaço urbano se encontra bloqueado, para pessoas que estão limitadas a viver no aperto de um quarto. Dessa forma é necessário "primeiro, ocupar o quarto, explorar possibilidades e lugares psíquicos, antes que a geografia da cidade" (Palombini, 2009, p. 300). O espaço urbano se compreende como um ensaio constante no exercício do AT, ou seja, a cidade que é atravessada pelo acompanhamento terapêutico não é apenas um palco ou uma peça secundária da clínica. Na prática desse dispositivo clínico, quando se percorre a cidade, cada aspecto urbano ganha importância: o que é imprevisível no cenário urbano, na mistura produzida pela cidade e na experiência de percorrer esse espaço é o que compõe a potência da experiência urbana no processo clínico do acompanhamento terapêutico.

Disconsini e outros (2013) retratam o espaço urbano de trabalho do AT como um lugar onde o usuário se conecta e cria 
vínculos: a clínica nesse espaço tem o objetivo de desinstitucionalizar o sujeito, passando de um modelo hospitalar para um modelo territorial, possibilitando uma outra produção da subjetividade. Com esse contato o usuário do AT se torna parte do local onde é inserido, pois passa a interagir e compor aquele espaço. Assim, os autores destacam o papel do coletivo como forma de desenvolver a diferenciação subjetiva e assim vivenciá-la. Dessa maneira, essas experiências inserem diferentes cotidianos na vivência desses indivíduos, pois o AT quebra o paradigma de que a loucura é algo a ser excluído socialmente (Disconsini e outros, 2013).

Bezerra e Dimenstein (2009) discutem o cuidado necessário do acompanhante terapêutico vinculado ao ato de desinstitucionalizar fabricado pelo AT através do campo social que ele percorre, pois a relação institucionalizante se dá por meio das relações de poder que habitam o enclausuramento da loucura. Como principal destaque de produção do AT as autoras destacam a experiência adquirida pelo acompanhante ao percorrer o espaço urbano e perceber os processos elaborados pela Reforma Psiquiátrica. Através da aplicação de métodos que valorizam o meio social, o AT atua na cidade possibilitando o contato do acompanhado com a multiplicidade do cotidiano urbano. O AT se apresenta como estratégia fundamental de reinserção social dos portadores de transtornos mentais.

$\mathrm{Na}$ perspectiva de Marques (2013) os movimentos de desterritorialização por meio do AT trabalham com objetivo de desinstitucionalizar o usuário, desterritorializando o manicômio, contribuindo para a produção de novos territórios existenciais para o acompanhado. A partir de interlocuções com concepções teóricas de Gilles Deleuze e de Félix Guattari, a autora destaca o pensamento como ferramenta de desterritorialização a partir da noção de criação gerada pelo ato de pensar. Dessa forma, o pensar e o desejar trabalham em direção ao desterritorializante, pois ambos podem produzir transformação de territórios existenciais através do que afeta as pessoas em suas relações com o espaço. Essas relações de desterritorialização e de reterritorialização no AT se dão por meio dos encontros do acompanhado com a rua e com as experiências que se constroem nesses trajetos.

De acordo com Azevedo e Dimenstein (2008), o AT possibilita o trabalho da relação da loucura com a sociedade ao proporcionar a circulação do acompanhado na cidade, pois com a institucionalização essa circulação lhe era negada. O espaço constitui processos do cotidiano dos quais o acompanhado foi retirado, e quando ele retorna a essa prática, 
volta a construir o seu convívio social com a cidade.

Para Pitiá (2006), o acompanhante terapêutico auxilia o acompanhado nos percursos pela cidade para possibilitar processos de interação no âmbito da experiência urbana. O campo social é impactado pelo que se constrói na clínica do AT, que visa potencializar o usuário diante de suas dificuldades psicossociais. Esse campo possibilita o "resgate" da autonomia do sujeito ao se produzir relações sociais que o acompanhado não possuía antes na e com a cidade, e essa oportunidade se dá a partir da saída dos espaços fechados do modelo manicomial. Ao se conectar com a exterioridade, o acompanhado se conecta tanto com o social quanto com elementos culturais necessários à cidadania. Assim, não se fazem necessários apenas novos espaços de atendimentos, mas o AT como dispositivo clínico mostra que é possível pensar em novas formas de atender pessoas com transtornos mentais sem retirar sua autonomia, ao propiciar outros modos de relação com a cidade.

\section{Considerações Finais}

A partir dessa revisão bibliográfica, percebemos que o Acompanhamento Terapêutico tem ganhado visibilidade no campo acadêmico da Psicologia, pois encontramos um volume considerável de publicações sobre a temática em periódicos científicos dessa área de conhecimento. É importante ressaltar que grande parte dessas publicações articulam a atuação de psicólogas e psicólogos - como acompanhantes terapêuticos - ao campo da Saúde Mental, indicando uma necessidade de compreender o AT como uma estratégia de intervenção transdisciplinar potente na efetivação da desistitucionalização proposta pela Reforma Psiquiátrica brasileira.

De acordo com as referências utilizadas no presente estudo, podemos entender que ter uma visão atenta sobre a singularidade e multiplicidade dos sujeitos acompanhados torna-se primordial para que a clínica do AT seja realizada, voltando- se a uma atenção psicossocial integral e não para o sujeito fragmentado como uma psicopatologia individualizada. Esse é um passo importante para entender que, na formação de psicólogas e psicólogos, o AT é uma prática possível e potente, que se tornou um marco histórico no desenvolvimento de práticas preconizadas pela Reforma Psiquiátrica. É necessário lembrar que no AT a participação da comunidade é tão importante quanto a dedicação da equipe inserida em um serviço de Saúde Mental. O sujeito não é isolado e autossuficiente, pois a subjetividade é produzida em espaços e na interação com 


\section{PSIQUIÁTRICA}

outros sujeitos. Compreendemos que a aposta do AT consiste em não dissociar o sujeito do seu território de existência, pois vivenciar qualquer tipo de transtorno não se reduz apenas a uma responsabilidade individual. Dessa forma, a clínica do AT volta-se ao acolhimento integral do usuário, e atenta continuamente aos processos de exclusão e discriminação que porventura podem surgir nas interações sociais.

Torna-se importante que o AT seja um dispositivo capaz de promover flexibilidade e frequentes discussões sobre a questão da reinserção social, sobre o exercício de autonomia, do qual o usuário de saúde mental, no modelo manicomial e hospitalocêntrico, é privado. O acompanhamento em saúde mental precisa ocorrer em redes que mantenham suas equipes abertas à relação com as diferenças que constituem os usuários, e não apenas dispostas a seguir um tecnicismo para tratar doenças, fragmentando o sujeito. Faz-se necessário entender que saúde mental e saúde física não são dissociadas e que a rede de atendimento precisa dar conta dessa indissociabilidade, até mesmo para desmistificar a ideia de que saúde mental é menos importante que saúde física.

Percebemos, ao longo do estudo, as mudanças ocorridas com os ideais da Reforma Psiquiátrica que cooperaram com o surgimento do AT e a importância, para a psicologia, da atuação nessa clínica, para a além dos muros das instituições. O AT foi se consolidando gradualmente por meio de um processo político e teórico, com diversos marcos e momentos históricos importantes, bem como através de diversas reflexões que questionavam a eficácia do modelo manicomial. O AT não se direciona apenas ao transtorno psíquico, mas também às ações de reinserção psicossocial, à responsabilização da comunidade no acompanhamento do sujeito e à inclusão da família nesse processo. É importante que a psicologia trabalhe na ampliação das elaborações teóricas e práticas que se articulam ao AT, pois, é um desafio ético manter uma abertura a outras possibilidades na prática transdisciplinar do AT, em sua inter-relação com o campo de formação e atuação da psicologia. 


\section{Referências bibliográficas}

Azevedo, T., \& Dimenstein, M. (2008) O Acompanhamento Terapêutico no cuidado em saúde mental. Estud. Pesqui. Psicol.., Rio de Janeiro, 8(3), 658-671. Recuperado de http://pepsic.bvsalud.org/scielo.php?script=sci_arttext\&pid=S1808$42812008000300008 \& \operatorname{lng}=$ pt\&nrm=iso

Bezerra, C.G., \& Dimenstein, M. (2009) Acompanhamento terapêutico na proposta de altaassistida implementada e hospital psiquiátrico: relato de uma experiência. Psic. Clin., Rio de Janeiro, 21(1) 15-32. Recuperado de http://www.scielo.br/scielo.php?script=sci_arttext\&pid=S0103-56652009000100002. doi.org/10.1590/S0103-56652009000100002

Chauí-Berlink, L.C. (2010) O Acompanhamento terapêutico e a formação do psicólogo: por uma saúde humanizada. Arquivos brasileiros de Psicologia. Rio de Janeiro, 62 (1). Recuperado de http://pepsic.bvsalud.org/scielo.php?script=sci_arttext\&pid=S180952672010000100010

Disconsini, A.M., Cavedon, B.Z., Greff, B.P., Chassot, C.S., Galvão, C., Leães, M.L. \& Carvalho, M.G. (2013) Acompanhamento terapêutico: andanças pelo dentro e fora da instituição. Psicologia \& Sociedade, Belo Horizonte, 25 (2), 65-72. Recuperado de: http://www.scielo.br/scielo.php?script=sci_arttext\&pid=S0102-71822013000600009

Estellita-Lins, C., Oliveira, V.M. \& Coutinho, M.F.C. (2006, setembro) Acompanhamento terapêutico: intervenção sobre a depressão e o suicídio. Psychê, São Paulo, 10(18), 151166. Recuperado de https://www.arca.fiocruz.br/handle/icict/6444

Foucault, Michel. (2012) História da loucura na Idade Clássica. São Paulo: Perspectiva.

Gonçalves, L. L. M. \& Barros, R. D. B. (2013) Função de publicização do Acompanhamento Terapêutico: A produção do comum na clínica. Psicologia \& Sociedade, Belo Horizonte, 25(2), 108-116. Recuperado de http://www.scielo.br/scielo.php?script=sci_arttext\&pid=S0102-71822013000600014

Gruska, V. \& Dimenstein, M. (2015) Reabilitação psicossocial e Acompanhamento terapêutico: equacionando a reinserção em saúde mental. Psic. Clin., Rio de Janeiro, 27(1), 101-122. Recuperado de http://www.scielo.br/pdf/pc/v27n1/0103-5665-pc-27-01-00101.pdf

Hermann, M. C. (2010) Acompanhamento terapêutico, sua criação em uma montagem institucional de tratamento e as ofertas de laço social. Estilos da clínica, São Paulo. 15(1), 40-59. Recuperado de http://www.journals.usp.br/estic/article/viewFile/46077/49702. doi.org/10.11606/issn.1981-1624.v15i1p40-59

Hirdes, A. (2009) A Reforma psiquiátrica no Brasil: uma (re) visão. Ciência \& Saúde Coletiva, Rio de Janeiro, 14(1), 297-305. Recuperado de 
http://www.scielo.br/scielo.php?script=sci_arttext\&pid=S1413-81232009000100036. doi.org/10.1590/S1413-81232009000100036

Marques, M. R. (2013) A prática do Acompanhamento Terapêutico como estratégia de expansão territorial: uma incursão cartográfica. Psicologia \& Sociedade, Belo Horizonte, 25(2). $\quad$ pp. 31-40. Recuperado de http://www.scielo.br/scielo.php?script=sci_arttext\&pid=S0102-71822013000600005. doi.org/10.1590/S0102-71822013000600005

Muylaert, M.A. (2006) AT como dispositivo clínico: uma perspectiva da esquizoanálise. Psychê, São Paulo, 10(18), 109-114. Recuperado de http://pepsic.bvsalud.org/scielo.php?script=sci_arttext\&pid=S1415-11382006000200011

Neto, M.L.A. \& Amarante, P. D. C. (2013) O Acompanhamento terapêutico como estratégia de cuidado na atenção psicossocial. Psicologia: ciência e profissão, Brasília, 33(4). Recuperado de http://www.scielo.br/scielo.php?script=sci_arttext\&pid=S141498932013000400014

Nogueira, A. B. (2009) O Acompanhamento terapêutico e sua caracterização em Betim e Belo Horizonte. Psicologia em Revista, Belo Horizonte, 15(2). 204 - 222. Recuperado de http://pepsic.bvsalud.org/scielo.php?script=sci_arttext\&pid=S1677-

$11682009000200013 \& \operatorname{lng}=\mathrm{pt} \& \mathrm{nrm}=\mathrm{iso} \& \operatorname{lng}=\mathrm{pt}$

Oliveira, R.W. (2013) Os caminhos da reforma psiquiátrica: acompanhamento terapêutico, propagação e contágio na metrópole. Psicologia \& Sociedade, Belo Horizonte, 25(2), 9094. Recuperado de http://www.scielo.br/scielo.php?script=sci_arttext\&pid=S0102$71822013000600012 \& \operatorname{lng}=\mathrm{en} \& \mathrm{nrm}=\mathrm{iso} \& \mathrm{t} \operatorname{lng}=\mathrm{pt}$

Pacheco, P. J. \& Menezes, V. C. S. (2014) Trajetórias do Acompanhamento terapêutico: a cidade e a loucura. Rev. Psicologia em Foco, Frederico Westphalen, 6(7), 65-81. Recuperado http://revistas.fw.uri.br/index.php/psicologiaemfoco/article/view/1568/1778

Palombini, A.L. (2006) Acompanhamento terapêutico: dispositivo clínico político. Psychê, São Paulo, 10(18), 115-127. Recuperado de http://pepsic.bvsalud.org/scielo.php?script=sci_arttext\&pid=S1415-11382006000200012

Palombini, A.L. (2009) Utópicas cidades de nossas andanças: Flânerie e amizade no Acompanhamento terapêutico. Fractal: Revista de Psicologia, Rio de Janeiro, 21(2), 295318. Recuperado de http://www.scielo.br/scielo.php?script=sci_arttext\&pid=S198402922009000200008. doi.org/10.1590/S1984-02922009000200008

Paravidini, J.L.L. \& Alvarenga, C. (2008) Acompanhamento terapêutico (AT) e saberes psicológicos: enfrentando a história. Gerais: Revista interinstitucional de Psicologia, Uberlândia, 1(2), 172-188. Recuperado de http://pepsic.bvsalud.org/scielo.php?script=sci_arttext\&pid=S1983$82202008000200009 \& \operatorname{lng}=\mathrm{es} \& \mathrm{nrm}=\mathrm{iso} \& \mathrm{t} \operatorname{lng}=\mathrm{pt}$ 
Pelliccioli, E. (2014) A prática psicológica do Acompanhamento terapêutico sob a perspectiva de uma articulação ética. Rev. Psicologia em Foco, Frederico Westphalen, 1(1). Recuperado de http://revistas.fw.uri.br/index.php/psicologiaemfoco/article/view/1128

Pitiá, A. C. A. (2006) Um olhar sobre o acompanhamento terapêutico pelo conceito reichiano de auto-regulação social. Psychê, São Paulo, 10(18), 141-150. Recuperado de http://pepsic.bvsalud.org/scielo.php?script=sci_arttext\&pid=S1415-11382006000200014

Pitiá, A. C. A. (2013) Acompanhamento terapêutico e ação interdisciplinar na atenção psicossocial. Psicologia \& Sociedade, Belo Horizonte, 25(2). 73-81. Recuperado de http://www.scielo.br/pdf/psoc/v25nspe2/v25nspe2a10.pdf.

Pitiá, A.C.A. \& Furegato, A.R.F. (2009) O Acompanhamento terapêutico (AT): dispositivo de atenção psicossocial em saúde mental. Interface comunicação, saúde e educação, Botucatu, 13(30), 67-77. Recuperado de http://www.scielo.br/scielo.php?script=sci_arttext\&pid=S1414-32832009000300007. doi.org/10.1590/S1414-32832009000300007

Ribeiro, A. M. (2009) A ideia de referência: o Acompanhamento Terapêutico como paradigma de trabalho em um serviço de saúde mental. Estudos de Psicologia, Natal, 14(1). Recuperado de http://www.scielo.br/scielo.php?script=sci_arttext\&pid=S1413294X2009000100010. doi.org/10.1590/S1413-294X2009000100010

Sereno, D. (2012) Sobre a ética no acompanhamento terapêutico (AT). Psic. Rev., São Paulo, 21(2), 217-232. Recuperado de https://revistas.pucsp.br/index.php/psicorevista/article/view/15135/11300

Silva, A.S.T. \& Silva, R.N. (2006) A emergência do Acompanhamento terapêutico e as políticas de saúde mental. Psicologia: ciência e profissão, Brasília, 26(2). Recuperado de http://www.scielo.br/scielo.php?script=sci_arttext\&pid=S1414-

$98932006000200005 \& \operatorname{lng}=\mathrm{en} \& \mathrm{nrm}=\mathrm{iso} \& \mathrm{t} \operatorname{lng}=\mathrm{pt}$

Silveira, R.W.M. (2016) Relação entre acompanhante e acompanhado: reflexões acerca do dispositivo amizade-clínica. Fractal: Revista de Psicologia, Rio de Janeiro, 18(3), 333340. Recuperado de http://www.scielo.br/scielo.php?script=sci_arttext\&pid=S198402922016000300333\&lng=en\&nrm=iso\&tlng=pt

Simões, C.H.D. \& Kirschbaum, D.I.R. (2005) Produção científica sobre o Acompanhamento terapêutico no Brasil de 1960 a 2003: uma análise crítica. Revista Gaúcha Enfermagem, Porto Alegre, 26(3), 392-402. Recuperado de http://www.seer.ufrgs.br/index.php/RevistaGauchadeEnfermagem/article/view/4569/249 6

Varella, M.R.D., Lacerda, F. \& Madeira, M. (2006) Acompanhamento terapêutico: da construção da rede à reconstrução do social. Psychê, São Paulo, 10(18), 129-140. Recuperado de http://pepsic.bvsalud.org/pdf/psyche/v10n18/v10n18a13.pdf

Vasconcelos, M. F. F., Machado, D. O., \& Mendonça Filho, M. (2013) Acompanhamento Terapêutico e Reforma Psiquiátrica: questões, tensões e experimentações de uma clínica antimanicomial. Psicologia \& Sociedade, Belo Horizonte, 25(2). 95-107. Recuperado de 
http://www.scielo.br/scielo.php?script=sci_arttext\&pid=S0102-71822013000600013. doi.org/10.1590/S0102-71822013000600013

Wachs, F., Jardim, C., Paulon, S. M., S. \& Resende, V. (2010) Processos de subjetivação e territórios de vida: o trabalho de transição do hospital psiquiátrico para serviços residenciais terapêuticos. Physis Revista de saúde coletiva, Rio de Janeiro, 20(3), 895-912. Recuperado de http://www.scielo.br/scielo.php?script=sci_arttext\&pid=S010373312010000300011. doi.org/10.1590/S0103-73312010000300011

\section{Os autores:}

Juliana Aguiar dos Santos Baptista é graduanda em Psicologia pelo Centro Universitário Augusto Motta UNISUAM, e-mail: aguiarjuliana.psi@hotmail.com

Rebeca Juliane da Silva Cavalcante é graduanda em Psicologia pelo Centro Universitário Augusto Motta UNISUAM, e-mail: bekcavalcante@ gmail.com

Maicon Barbosa é doutor em Psicologia [Estudos da Subjetividade] pelo programa de Pós-Graduação em Psicologia da Universidade Federal Fluminense. Professor do curso de Psicologia do Centro Universitário Augusto Motta - UNISUAM, e-mail: maiconbars@ hotmail.com

Recebido em: 16/12/2017

Aprovado em: 28/12/2018. 